\title{
A complexidade textual na dinâmica argumentativa $^{i}$
}

\author{
Ananias Agostinho da Silva* \\ Maria da Graça dos Santos Faria** \\ Mariza Angélica Paiva Brito ${ }^{* * *}$
}

\begin{abstract}
Resumo: Este trabalho trata sobre a dinâmica argumentativa na complexidade dos textos. De modo geral, busca refletir sobre o caráter argumentativo dos textos com vistas a postularmos, a partir de Cavalcante (2016), uma classificação entre os textos de dimensão argumentativa e os textos de visada argumentativa. Para tanto, estabelecemos uma interface entre a teoria da argumentação no discurso (AMOSSY, 2018) e a Linguística Textual, discutindo acerca de como certos parâmetros da análise textual podem contribuir em potencial para a compreensão do funcionamento do discurso em várias modalidades argumentativas, sobretudo a polêmica. Palavras-chave: Complexidade textual. Argumentação. Linguística Textual. Polêmica.
\end{abstract}

\begin{abstract}
This work deals with the argumentative dynamics in the complexity of the texts. In general, it seeks to reflect on the argumentative character of the texts with a view to postulating, from Cavalcante (2016), a classification between the texts of argumentative dimension and the texts of argumentative aim. For that, we established an interface between the theory of argumentation in discourse (AMOSSY, 2018) and Textual Linguistics, discussing about how certain parameters of textual analysis can potentially contribute to the understanding of the functioning of discourse in various argumentative modalities, especially the polemic.
\end{abstract}

Keywords: Textual complexity. Argumentation. Text Linguistics. Polemic.

Resumen: Este trabajo aborda la dinámica argumentativa en la complejidad de los textos. En general, busca reflexionar sobre el carácter argumentativo de los textos para postular, a partir de Cavalcante (2016), una clasificación entre los textos de dimensión argumentativa y los textos de finalidad argumentativa. Para eso, establecimos una interfaz entre la teoría de la argumentación en el discurso (AMOSSY, 2018) y la lingüística textual, discutiendo cómo ciertos parámetros del

\footnotetext{
i Agradecemos à professora Mônica Magalhães Cavalcante, pela leitura atenta do texto e pelas contribuições apresentadas ao aprimoramento desta versão final.

* Doutor em Estudos de Linguagem e professor do curso de Pedagogia da Universidade Rural do SemiÁrido (UFERSA). http://orcid.org/oooo-0001-5442-5133

** Doutora em Linguística pela Universidade Federal do Ceará (UFC) e professora associada do Departamento de Letras e do programa de Pós-Graduação em Letras da Universidade Federal do Maranhão (UFMA). http://orcid.org/0000-0002-2704-0497

${ }^{* * *}$ Doutora em Linguística pela Universidade Federal do Ceará (UFC) e professora adjunta da Integração Internacional da Lusofonia Afro-brasileira (UNILAB). http://orcid.org/oooo-0001-5375-5480
} 
análisis textual pueden contribuir potencialmente a la comprensión del funcionamiento del discurso en diversas modalidades argumentativas, especialmente el controvertido.

Palabras clave: Complejidad textual. Argumentación Lingüística textual. Polemica.

\section{Introdução}

No horizonte teórico da Linguística Textual, o texto, seu objeto, tem sido tomado como entidade multifacetada, resultante de um processo extremamente complexo de interação social e de construção de sentidos - unidade negociada e contextualizada de coerência (CAVALCANTE, 2016) - e de sujeitos, de conhecimento, de linguagem $(\mathrm{KOCH}, 2004)$. Compreendido como um evento de natureza altamente complexa, o texto é o objeto de estudo sobre o qual se pode investigar diferentes fatores que atuam de maneira articulada no processo de construção de sentidos. Dentre esses fatores, estão fenômenos de natureza diversa: linguística, semântica, pragmática, discursiva, enunciativa e argumentativa. Se, por um lado, a consideração desses fatores ilustra o caráter multifacetado do texto, por outro, revela a complexidade necessária ao exame desse objeto.

Assim, para apreender melhor a complexidade textual, é necessário, também, compreender o aspecto argumentativo do texto, sob o viés de uma argumentação no discurso, considerando que todos os textos são argumentativos em diferentes graus, se levarmos em conta a não neutralidade da linguagem apontada por Bakhtin (1997), ou seja, o pressuposto de que nenhum texto é neutro, porque os sujeitos só enunciam em relação a valores sociais, e sempre orientados para o outro. Isso implica considerar a argumentação como uma dimensão constitutiva do texto, ainda que manifestada em graus distintos, a depender de vários fatores como o gênero do discurso, a modalidade argumentativa, as estratégias de textualização agenciadas à elaboração dos sentidos que atendam aos projetos de dizer do locutor, dentre outros.

Tomando em conta esses aspectos, neste trabalho, buscamos refletir a respeito da dinâmica argumentativa na complexidade textual, isto é, discutir acerca do caráter argumentativo dos textos considerando as contribuições e a produtividade que certas 
categorias da Linguística Textual podem apresentar à análise da argumentatividade nos textos. Conforme esclarece Cavalcante (2016), não se trata de reivindicar para a Linguística Textual a tarefa de teorizar sobre a argumentação, mas de compreendê-la como fenômeno constitutivo do texto e a sua motivação para a análise de diversas estratégias de organização textual. Teoricamente, cabe-nos salientar, neste trabalho, a relação argumentativa contemplada pela análise do discurso (MAINGUENAU, 2008; AMOSSY, 2011, 2017, 2018) e as pesquisas desenvolvidas no âmbito da Linguística Textual, sobretudo, por Cavalcante (2016), Macedo e Cavalcante (2019) e Cavalcante et alii (2019).

Desta forma, primeiro, investigamos como a noção de argumentatividade é compreendida pela análise do discurso, especialmente apoiada na concepção da argumentação no discurso de Amossy (2017, 2018). Em seguida, destacamos como essa autora elabora a concepção de modalidades argumentativas fundamentadas a partir do critério de gêneros do discurso, para, então, dar evidência à modalidade polêmica construída pelo dissenso a partir do debate em torno de tema de interesse social e também calcada numa forte oposição de ideias. Finalmente, salientamos um posicionamento teórico-metodológico dentro do campo da Linguística Textual que justifica como a organização textual utiliza de estratégias argumentativas para tornar o dizer persuasivo nas práticas discursivas, assumindo que todos os textos têm uma dimensão argumentativa, mas só alguns apresentam visada argumentativa, conforme Cavalcante (2016).

\section{Análise do discurso e argumentação}

Historicamente, as teorias da análise do discurso e as teorias da retórica ou da argumentação desenvolveram contornos metodológicos e também analíticos distintos mesmo que, não muito raramente, numa ocasião ou noutra, seus corpora de análise pudessem se compatibilizar. Bem no início da década de noventa do século passado, 
Maingueneau (1991) comentou a respeito de não ser possível integrar a retórica aos prolegômenos da análise do discurso. Em sua explicação, a problemática do sujeito encontra-se na origem dessa cisão entre as duas áreas: enquanto a retórica supõe a existência de um sujeito soberano, que detém controle absoluto de seu dizer, o sujeito da análise do discurso é completamente atravessado pelos posicionamentos ideológicos, advindos das formações discursivas. A esse aspecto da agentividade do sujeito, Amossy (2016) rebate a desconfiança da análise do discurso sobre a argumentação retórica, sobretudo a de tradição aristotélica, com universais analíticos e taxonomias atemporais.

Amossy (2018) reivindica a necessidade de a análise do discurso integrar plenamente ao seu dispositivo teórico-metodológico a argumentação enquanto elemento constitutivo do discurso. Segundo a autora, não se pode dissociar a análise dos argumentos ou mesmo da organização verbal de um raciocínio lógico do conjunto do discurso que os constroem. A cada esquema abstrato de organização interna da argumentação, pode ser conferido um sentido e uma força ilocucionária específica num texto único e irrepetível. Evidentemente, não se trata apenas de uma mera sobreposição de categorias teóricas, mas de uma complementaridade entre essas áreas que supõem uma estreita ligação entre linguagem e retórica num espaço de reflexão mais amplo. Trata-se de uma abordagem sociodiscursiva da argumentação que se ocupa não só em identificar argumentos pela conferência de uma taxonomia prévia estabelecida por definição, mas sim de ver como eles são arranjados e como funcionam no uso.

Nessa perspectiva sociodiscursiva, entende-se a argumentação a partir de uma concepção mais alargada, em sua extensão máxima, como a tentativa de modificar, de reorientar, ou mesmo, de reforçar, pelos recursos da linguagem, a visão das coisas por parte dos interlocutores (AMOSSY, 2011). Com efeito, a noção de argumentação é constitutiva dos discursos de finalidade persuasiva, ou seja, aqueles que defendem ou refutam explicitamente uma tese, mas também de todos os outros discursos que, de alguma maneira, orientam os modos de pensar, ver e sentir dos interlocutores, ou seja, discursos que não visam primeiramente à persuasão, mas que podem modificar as representações dos interlocutores, porque exercem sobre eles alguma influência. Essa 
concepção justifica a inserção da argumentação na análise do discurso e sugere ainda o estudo da argumentatividade em todos os textos, sob a forma de diversos gêneros ${ }^{1}$.

O deslocamento proposto pela autora considera a existência de uma dimensão argumentativa constitutiva de todos os discursos, porque sempre que um discurso é produzido, ele compartilha "um ponto de vista, uma forma de reagir a uma situação ou de sentir um estado de fato" (AMOSSY, 2016, p. 174), por isso, para a autora, a argumentação é "uma tentativa de fazer ver as coisas de uma determinada maneira e de agir sobre o outro" (AMOSSY, 2011, p. 131). Não se trata exatamente de uma absoluta dissolução da argumentação na linguagem, como se esta pudesse ser em si mesma substituída por aquela, porque a relação que se coloca é de outro nível. Quando defende que todo discurso possui uma dimensão argumentativa, a autora sugere que todo discurso implica uma maneira de se perceber determinado assunto ou objeto (AMOSSY, 2012, 2016). E o posicionamento que esse discurso constrói sempre se opõe, ainda que implicitamente, a um outro ponto de vista.

Todavia, ainda conforme observa Amossy (2011, p. 131), “a posição contrária não precisa ser apresentada na íntegra, na medida em que a palavra é sempre uma resposta à palavra do outro, uma reação ao dito anterior que ela confirma, modifica ou rejeita”. Noutras palavras, mesmo que um discurso não evidencie explicitamente a defesa de um ponto de vista, sua orientação argumentativa aparece em alguns traços de linguagem (modalidades, formas axiológicas, conectores, seleção lexical). E ainda, é possível que não se evidencie explicitamente a orientação argumentativa do discurso, já que ela pode ser sempre reconstruída na interdiscursividade. Ora, nisto reside o fundamento do princípio do dialogismo bakhtiniano: um enunciado é sempre orientado para o outro, ao qual ele reage, mesmo que implicitamente, numa atitude responsiva e ativa. Assim, necessariamente, em todo discurso há uma dimensão argumentativa, porquanto ele confirma, refuta ou problematiza posições anteriores, expressas de modo preciso por um interlocutor, ou de modo difuso nos embates interdiscursivos (AMOSSY, 2012).

\footnotetext{
${ }^{1}$ Diferentemente da retórica aristotélica, que privilegiava o estudo dos gêneros jurídico, deliberativo e epidítico, estamos adotando a noção bakhtiniana de gêneros do discurso.
} 
Se se considera esse alargamento da definição de argumentação, a autora propõe distinguir discursos que apenas possuem uma dimensão argumentativa de discursos de visada argumentativa, aqueles que constroem um arrazoado em defesa de uma tese. Para evitar confusões, Amossy (2018) esclarece que os discursos marcados por estratégia de persuasão programada manifestam uma intenção argumentativa (AMOSSY, 2011), um modo expressa e reconhecidamente persuasivo de argumentar denominado de visada argumentativa. É o que se verifica em gêneros prototipicamente argumentativos, como uma carta de intenções, um discurso político eleitoral ou um anúncio publicitário. Os textos que se realizam nesses gêneros sempre buscam persuadir os interlocutores a respeito da validade de uma tese, apelando, para isso, a estratégias argumentativas previamente elaboradas. Diferem dos textos que apenas têm uma tendência a orientar as representações dos interlocutores, sem, necessariamente, buscar convencê-los sobre uma opinião, como acontece com os gêneros narrativos.

Nesse enquadre teórico, portanto, a argumentação está sendo entendida como

[...] os meios verbais que uma instância de locução utiliza para agir sobre seus alocutários, tentando fazê-los aderir a uma tese, modificar ou reforçar as representações e as opiniões que ela lhes oferece, ou simplesmente orientar suas maneiras de ver ou de suscitar um questionamento sobre um dado problema. (AMOSSY, 2012, p. 47).

Como é constitutivamente dialógica e está constitutivamente no discurso, a argumentação não poderia ser tomada enquanto propriedade exclusiva de alguns discursos. Ela pode até aparecer de maneira mais saliente em alguns textos (é o caso de textos de visada argumentativa) ou de maneira menos incisiva noutros (os discursos de dimensão argumentativa). Mas, em todo caso, a argumentatividade está fundamentalmente imbrincada nos discursos e, como observa Cavalcante (2016) em todos os textos. Por esse motivo, Amossy $(2011,2012)$ recomenda entendê-la na escala de um continuum da argumentatividade: num polo, estaria o confronto explícito de teses antagônicas; no outro, os discursos de expressão espontânea de pontos de vista (sem visada argumentativa). Então, a argumentação deverá ser tomada numa dimensão modular, considerando que os discursos podem apresentar distintos graus de 
argumentatividade, a depender de componentes vários relativos aos usos da língua em situação.

\section{Modalidades argumentativas}

Ao sugerir a argumentatividade como característica constitutiva dos discursos, Amossy (2017) depara-se com uma dificuldade metodológica: se é verdade que todo discurso possui uma dimensão argumentativa, por outro lado, não se pode ignorar que o grau de argumentatividade dos discursos pode variar em detrimento da implicação da situação e do dispositivo da enunciação na verbalização de um ponto de vista no discurso. À vista disso, a autora elabora a noção de modalidade argumentativa, para referir-se aos diversos e distintos "tipos de trocas argumentativas que, atravessando os gêneros do discurso, modelam a forma como a argumentação funciona tanto num quadro dialogal quanto num dialógico.” (AMOSSY, 2008, p. 232). Assim, as interações persuasivas supõem estruturas de trocas argumentativas que condicionam os modos de argumentar. Se o uso recorrente dessas estruturas constrói certas regularidades, também institui padrões particulares de regimes discursivos em quadros institucionais diferentes. A autora explica:

Não tentamos influenciar um júri no curso de um processo como tentamos fazer eleger um candidato em uma campanha eleitoral, ou fazer partilhar nossas opiniões por um amigo em uma conversação familiar, ou suscitar a reflexão do leitor sobre um estado do mundo em um texto romanesco (AMOSSY, 2005, p. 167).

Essas diferenças se acentuam sobremaneira a partir do critério do gênero. Sim, porque, de acordo com Amossy (2017), só é possível argumentar no âmbito de um quadro discursivo (e também institucional), isto é, de um gênero do discurso que determina as regras de funcionamento e de restrições da interação verbal. Assim, para cada troca argumentativa pretendida, os gêneros do discurso dispõem de modelos já endossados e 
repertoriados que determinam um cenário de expectativas. A partir do gênero, inclusive, é possível arrolar ainda outros parâmetros que caracterizam as modalidades argumentativas. Macedo e Cavalcante (2019) observam, com base em Amossy (2008), pelo menos três desses parâmetros: os papéis desempenhados pelos participantes no dispositivo da enunciação (se parceiros ou adversários), a maneira pela qual ocorre a tentativa de persuasão (se apaixonada, racional, colaborativa ou instrutiva) e a maneira como o interlocutor é concebido (ser de razão ou de sentimento, aluno ou discípulo, cúmplice ou rival etc.).

Conforme esses parâmetros, seria possível distinguir diferentes possibilidades de modalidades argumentativas, como a demonstrativa, a patêmica, a pedagógica, a negociada, a coconstruída e a polêmica, dentre outras possibilidades, ainda a serem exploradas. Metodologicamente, Amossy (2017) explica que essas modalidades podem ser distribuídas num continuum: numa das extremidades, estaria a polêmica, ou seja, o desacordo profundo gerado pelo choque de duas teses antagônicas; na outra, a argumentação persuasiva que não ataca a posição contrária abertamente ou nem mesmo menciona essa posição, como se não apresentasse nenhuma visada de influência; no centro do continuum, estaria a argumentação como troca regrada de teses antagônicas. Macedo e Cavalcante (2019) buscaram elucidar essa organização com o seguinte esquema:

Esquema o1 - Continuum das modalidades argumentativas

\begin{tabular}{|c|c|c|}
\hline $\begin{array}{c}\text { - Choque entre teses } \\
\text { antagônicas (modalidade } \\
\text { polêmica) }\end{array}$ & $\begin{array}{c}\text { • Discursos monogeridos que } \\
\text { propõem levar o auditório a } \\
\text { aderir a uma tese (modalidade } \\
\text { demonstrativa); } \\
\text { • Interações face a face em que } \\
\text { os participantes negociam um } \\
\text { acordo (modalidade negociada); } \\
\text { • Situações de diálogo em que } \\
\text { os participantes se esforçam } \\
\text { para coconstruir uma resposta } \\
\text { para uma questão dada } \\
\text { (modalidade de coconstrução). }\end{array}$ & $\begin{array}{l}\text { - Discursos de caráter } \\
\text { informativo ou narrativo } \\
\text { (desprovidos de visada } \\
\text { argumentativa) }\end{array}$ \\
\hline
\end{tabular}

Fonte: Macedo e Cavalcante (2019).

Revista Investigações, Recife, v. 33, No especial, Texto: gêneros, interação e argumentação - III Workshop de Linguística Textual, p. 27 - 44, 2020 ISSN Digital 2175-294X 
Nessa escalaridade, distribuem-se diferentes modalidades argumentativas, isto é, diferentes modos de argumentar estruturados em esquemas de trocas de interação. Essas modalidades atravessam os diversos gêneros do discurso conforme os objetivos pretendidos com a argumentação e a relação entre os interlocutores. Sem a pretensão de uma listagem exaustiva e estanque, porque seria possível identificar outras maneiras pelas quais se pode argumentar, a autora caracteriza essas modalidades da seguinte maneira:

a) Modalidade demonstrativa: "uma tese é apresentada pelo locutor, num discurso monogerido ou poligerido, a um auditório cuja adesão ele quer obter por meio da demonstração razoável, do raciocínio articulado apoiado em provas”. É recorrente em gêneros do discurso como a redação escolar, o artigo de opinião, o artigo acadêmico e a tese de doutoramento.

b) Modalidade pedagógica: "um locutor se coloca em posição superior e leva à reflexão um auditório que ocupa o lugar de aprendiz". Aparece em gêneros como o romance, a reportagem e o livro didático (discursos monogeridos) ou ainda em gêneros de discurso poligerido, como a aula.

c) Modalidade patêmica: "uma tese e um ponto de vista são apresentados no discurso monogerido ou num diálogo, de modo a 'tocar' o auditório, para obter sua adesão”. Encontra-se em gêneros como a canção, o poema e a declaração de amor.

d) Modalidade por coconstrução: "os participantes coconstroem a resposta para o problema levantado em conjunto”. É o que acontece em interações dialogais como a reunião de condomínio, a reunião de colegiado.

e) Modalidade negociada: "os parceiros que ocupam posições divergentes, e mesmo conflituosas, se esforçam para encontrar uma solução comum para o problema que os divide e para chegar a um consenso através do compromisso". Observa-se em gêneros como a audiência de conciliação ou a negociação comercial. 
f) Modalidade polêmica: o choque de teses contrárias, um modo de gestão do conflito, um conjunto de intervenções antagônicas sobre uma questão social irresolvível (AMOSSY, 2008, p. 234-235).

É sobre a modalidade polêmica que Amossy se debruça mais, pois a ela dedica uma obra inteira, da qual falaremos na seção a seguir.

\section{A modalidade polêmica}

No escopo dessa teoria da argumentação no discurso, conforme o desenho de Amossy (2011, 2012, 2016, 2017), a polêmica é tomada como sendo uma modalidade argumentativa que se distingue pela polarização extrema e pela confrontação radical de posições antagônicas. Nas sociedades democráticas contemporâneas, a polêmica se desenvolve de forma consistente em espaços públicos (sejam físicos ou virtuais) a partir do debate instaurado em torno de tema de interesse social numa determinada cultura. Nesse sentido, uma polêmica é sempre demarcada cultural e temporalmente, ou seja, certo acontecimento pode desencadear forte embate de opiniões numa dada sociedade, mas passar despercebido numa outra ou mesmo ser indiferente para seus membros. De igual maneira, uma polêmica atualizada no espaço público consegue ser altamente inflamada quando do seu surgimento, porquanto se desenvolve em torno de uma questão da atualidade, porém, quando passa, pode acabar facilmente no esquecimento, porque sua duração, como acontecimento, é efêmera.

A polêmica compreende um fenômeno sociodiscursivo, já que se trata de "uma manifestação discursiva sob a forma de embate, de afrontamento brutal, de opiniões contraditórias" (AMOSSY, 2017, p. 53), que acontece num confronto verbal no espaço público. Ela se constrói discursivamente e modela o diálogo inconciliável entre pontos de vista antitéticos. Constitui a essência do dissenso e está indissoluvelmente ligada ao desacordo, ao desentendimento, ao mais severo divórcio de opiniões.

Por essa ancoragem no conflituoso, a polêmica é descrita pela autora segundo três elementos característicos: 
- a dicotomização como modo de gestão do conflito entre discursos;

- a polarização social;

- a desqualificação do adversário.

Esses são os traços definitórios da polêmica, mas, de maneira mais secundária, ela ainda pode ser intensificada pelo recurso à violência verbal e pelo apelo às emoções, conforme aponta Amossy (2017) e conforme se observa nas análises de Silva (2018), Brito e Oliveira (2018), Cabral e Lima (2018), dentre outros.

Os discursos que atualizam uma polêmica apresentam oposições entre ideias, construídas como dicotomias, sem compromisso algum com possibilidade de acordo. De fato, a polêmica instaura uma dicotomização entre pontos de vista inconciliáveis, cujo confronto de opiniões não tem nenhuma alternativa intermediária de solução, mas que, a todo momento, radicaliza e acentua ainda mais o dissenso. São posições que se excluem mutuamente, que se anulam uma a outra discursivamente, apesar de circularem simultaneamente no espaço público. Na verdade, a construção de uma dicotomização ocorre sempre num contexto preciso, na dependência de contextos socioculturais, de crenças ideológicas, de necessidades argumentativas, de circunstâncias históricas ou geográficas (AMOSSY, 2017). A identificação dos sujeitos com posições congeladas em pares dicotômicos pode ser modificada conforme se alteram também essas condições.

Como efeito sociodiscursivo da dicotomização, a polêmica instaura a operação de polarização. As posições antagônicas que acionam a polêmica são assumidas por atores sociais e se concretizam em seus discursos. Porém, no plano de uma estrutura actancial, esses atores encenam papéis temáticos (actantes) diametralmente opostos: proponente, oponente e um terceiro. "Não se trata aqui mesmo de pessoas, mas de papéis (temáticos): defensor da posição proposta, opositor dessa posição, ouvinte-espectador da confrontação" (AMOSSY, 2017, p. 56). Porque na argumentação polêmica não há possibilidade alguma de acordo, de vez que proponente e oponente não abrirão mão nunca de seus posicionamentos, o terceiro é o alvo da persuasão, ou seja, importa aos actantes conquistá-lo como modo de fortalecer um lado da polarização. Nesse sentido, a retórica da polarização fundamenta-se em um fenômeno social, pois opera um 
movimento de agrupamento por identificação dos actantes com uma opinião defendida e, por outro lado, de execração da tese oposta.

Para acentuar a dicotomização das posições, os lados polarizados recorrem a manobras de desqualificação do outro. “A exacerbação de oposições se concretiza numa divisão em grupos antagônicos em que cada um afirma a sua identidade social opondose e fazendo do outro o símbolo do erro e do mal" (AMOSSY, 2017, p. 58, grifo nosso). Trata-se de uma estratégia retórica para desacreditar o adversário, um movimento de difamação e de deslegitimação do outro, definido como sendo defensor de uma posição caracterizada por sua má fé (não autêntico) e suas más intenções. Para tanto, o proponente pode apelar a um conjunto de procedimentos discursivos e retóricos, dentre os quais: a negação, a ironia, a reformulação, a hipérbole, os jogos sistemáticos de oposição, o manejo direcionado do discurso relatado ou a marcação axiológica e outros. Esses procedimentos operam a desqualificação do discurso do adversário (logos) ou mesmo lançam algum descrédito sobre a imagem do adversário (ethos). O argumento ad hominem: não basta desqualificar o discurso do adversário, mas a sua própria imagem, ou a do grupo que representa, também parece precisar ser afetada.

Ao colocar a polêmica no campo da argumentação, já que o discurso polêmico conjectura o emprego de várias estratégias argumentativas, e não para conduzir a um acordo de posições, mas para marcar um ponto de vista e marcar o descrédito ante o adversário e o seu discurso, Amossy (2017) avalia que a polêmica preenche funções sociais fundamentalmente importantes em sociedades democráticas pluralistas. Ainda que em sua virulência, em seus excessos, ela permita o confronto público de conflitos insolúveis: dois grupos opostos podem dividir o mesmo espaço público reconhecendo mutuamente o direito à liberdade de expressão. É a polêmica que permite a formação de comunidades de protesto e de ação pública necessárias ao funcionamento pleno da democracia. Assim, sobretudo quando vivemos momentos de ameaça aos direitos, de violação do estado democrático de direito, assegurar o funcionamento da polêmica como possibilidade de manifestação de divergências de opinião é inevitável. 


\section{Interfaces com a Linguística Textual}

A tradição em estudos da Linguística Textual incluiu a argumentação como um pressuposto inegável na análise de diversas estratégias de organização textual. São muitas as abordagens que, a partir de diferentes orientações metodológicas, tomam a argumentação como motivação em suas análises de textos (CAVALCANTE, 2016). De igual maneira, também o diálogo entre essa disciplina e a Análise do Discurso tem se estreitado significativamente, sobretudo porque a distinção entre os seus objetos tornou-se inextricável, embora se reconheçam as especificidades de cada movimento teórico (MARCUSCHI, 20o8). Ora, sendo o texto uma entidade multifacetada e com variados níveis de complexidade, considerar o seu funcionamento discursivo é muito imperativo. Na agenda de trabalho da Linguística Textual, importantes investidas têm sido feitas no tratamento discursivo de categorias textuais, conforme se pode verificar, por exemplo, nos trabalhos de Cavalcante (2009, 2011) a respeito da referenciação.

É por isso que advogamos em favor de um posicionamento teórico-metodológico que responda pela interface necessária entre essas três áreas. É evidente que não se trata de uma reinvindicação para situar a argumentação e o discurso como objetos de teorização da Linguística Textual, segundo esclarece Cavalcante (2016), mas sim de considerar como critérios de análise dessa disciplina contribuem para fazer funcionar o dispositivo teórico-metodológico que articula a argumentação e a análise do discurso numa teoria da argumentação no discurso. Esse empreendimento se justifica porque são as estratégias de organização textual que abonam os arranjos dispostos por um locutor para tornar um projeto de dizer persuasivo no âmbito de práticas discursivas. Se a argumentação é constitutiva dos discursos (entendidos como enunciação), e se o discurso se realiza somente em textos (enunciados únicos), Cavalcante (2016) assume que todos os textos têm uma dimensão argumentativa, mas que só alguns apresentam visada argumentativa.

Nessa direção, a argumentação não é somente constitutiva de todo discurso, mas também de todo texto, ou seja, os textos são todos argumentativos, mesmo que em graus 
diferentes. Na verdade, desde a década de noventa, Adam (1990), situado no escopo da Linguística Textual, já anunciava que, de um ponto de vista pragmático ou configuracional, todo texto é argumentativamente orientado. Esse autor entende a argumentação em duas abordagens: a argumentação em geral, mais ampla, tomada mesmo como uma função da linguagem, porque é a ela inerente, e a argumentação como unidade composicional (sequência argumentativa) - a argumentação limita-se a um conjunto de textos cuja forma de composição caracteriza-se pela defesa explícita de uma tese. A noção geral de argumentação revela-se no nível do discurso (crenças ou representações são construídas) e também no nível da organização pragmática da textualidade (escolhas textuais dos sujeitos para alcançar propósitos comunicativos) (ADAM, 2019).

Podemos observar que, na verdade a distinção entre dimensão argumentativa e visada argumentativa se estabelece não ao nível do discurso, mas ao nível do texto. A distinção que faz a autora, no nível do discurso, entre visada argumentativa e dimensão argumentativa, fundamenta-se em categorias do texto. Esse aspecto tem sido já apontado por alguns linguistas do texto (CAVALCANTE et alii, 2018; CAVALCANTE et alii, 2019), que, por inspiração de Amossy (2017), defendem a existência de textos com visada argumentativa e de uma dimensão argumentativa para os textos. Assim, em estreito diálogo também com Adam (2019), defendemos que, de um ponto de vista pragmático e retórico, todo texto possui uma dimensão argumentativa, mas somente alguns textos apresentariam uma visada argumentativa. Nesses últimos textos, verificamos uma estrutura sequencial dominante na seleção de argumentos hierarquicamente organizados para a defesa de uma tese. Assim, conforme esclarecem Cavalcante et alii (2018), somente quando o texto tem sequência argumentativa dominante é que se pode dizer que ele apresenta visada argumentativa.

É a presença de uma estrutura sequencial argumentativa dominante que permite reconhecer textos de visada argumentativa. Também a dimensão argumentativa pode ser observada no nível textual, pois, é no texto, considerando suas escolhas textuais, que o sujeito encontra maneiras de alcançar seu interlocutor, em relação a uma questão social. Em vista disso, mesmo quando os textos não sustentam a defesa explícita de uma 
tese, ainda assim, apresentam uma dimensão argumentativa porque influenciam, de alguma maneira, o seu interlocutor.

Esse raciocínio encontra respaldo substancial na definição de argumentação desenvolvida por Amossy (2018), como a tentativa de modificar, de reorientar, ou mais simplesmente, de reforçar a visão do interlocutor pelos recursos da linguagem. As escolhas textuais realizadas pelos sujeitos implicam maneiras de agir sobre os discursos, sobre os interlocutores (de ser argumentativo, de colocar os argumentos em textos), numa atividade permanente de negociação de sentidos. Pensar a argumentação nessa concepção mais ampliada é bastante apropriada para os estudos em Linguística Textual porque permite tratar dos mais variados textos, e não somente aqueles que envolvem um problema social ou que tratam uma polêmica no espaço público (CAVALCANTE et alii, 2018).

\section{Conclusão}

O pressuposto de que a argumentatividade nos textos relaciona-se, sobretudo, com as escolhas textuais que faz o sujeito para alcançar seu propósito comunicativo confere importância relevada à agentividade. Nesse contorno, a concepção de sujeito na Linguística Textual não é extremista, ou seja, não é completamente constrangida pelos posicionamentos ideológicos, conforme se acredita na Análise do Discurso, nem tampouco o sujeito é soberano, com controle absoluto de seu dizer e dos sentidos do texto, como se supõe na Nova Retórica.

Na verdade, a Linguística Textual considera os condicionamentos discursivos, mas também leva em conta o livre arbítrio do sujeito, ou seja, a capacidade de evidenciar no cotexto marcas de seus posicionamentos discursivos (CAVALCANTE, 2016). O sentido do texto é uma unidade de coerência negociada e contextualizada na interação, isto é, não está em dependência da vontade do locutor, mas, por outro lado, se relaciona 
fundamentalmente com as suas intenções, com os seus objetivos de comunicação e com as condições contextuais da interação.

Portanto, no horizonte da Linguística Textual, a argumentação se evidencia nos textos e mobiliza a ativação de diversos recursos linguageiros selecionados pelo sujeito (dotado de uma intencionalidade) com vistas a influenciar o outro de alguma maneira.

A argumentação depende substancialmente das escolhas textuais que são operadas pelo sujeito, dentre diversas outras possíveis, e que funcionam como diferentes tipos de estratégias argumentativas mobilizadas a partir não somente do uso de recursos lexicais e gramaticais (linguísticos, como denomina a teoria da argumentação no discurso), mas também de certos mecanismos da ordem do texto, como escolhas referenciais, intertextuais, dialógicas, polifônicas, composicionais, de organização tópica, coesivas, genéricas etc.

É nesse sentido que, acompanhando Cavalcante (2016), reivindicamos um estudo da argumentação numa abordagem interdisciplinar focada na Linguística Textual, que considere os parâmetros de análise concernentes ao texto. Se é possível uma interface entre a Linguística Textual, a Análise do Discurso e a argumentação, conforme sugerido acima, alguns critérios de análise da Linguística Textual podem ser utilmente convocados para a análise das diversas modalidades de argumentação tratadas por Amossy (2008) no âmbito de uma teoria da argumentação no discurso.

Num cauteloso exercício de síntese, Cavalcante (2016) menciona várias categorias que viabilizam o estudo do funcionamento da argumentação nos textos: o gênero do discurso, as sequências textuais, a organização tópica, a intertextualidade, a heterogeneidade enunciativa e o gerenciamento de vozes, a referenciação, a polidez linguística e as formas de metadiscurso. Levando em consideração esses parâmetros, algumas investidas pioneiras já demonstram a produtividade da utilização de critérios da ordem do texto na análise de estratégias de desvelamento da argumentatividade, como, por exemplo, os trabalhos de Brito e Oliveira (2018) e de Macedo e Cavalcante (2019), a respeito da modalidade polêmica. 


\section{Referências}

ADAM, J. M. Eléments de linguistique textualle. Liége: Mardaga, 1990.

. Texto: tipos e protótipos. Trad. de Mônica Magalhães Cavalcante et alii. São Paulo: Contexto, 2019 .

AMOSSY, R. O ethos na intersecção de disciplinas: retórica, pragmática e sociologia dos campos. In: (Org.). Imagens de si no discurso: a construção do ethos. Tradução de Dilson Ferreira da Cruz et alii. São Paulo: Contexto, 2005.

As modalidades argumentativas do discurso. In: LARA, G.; MACHADO, I.; EMEDIATO, W. (Orgs.). Análises do discurso hoje. v. o1. Rio de Janeiro: Nova Fronteira, 2008. p. 231-254.

- Argumentação e Análise do Discurso: perspectivas teóricas e recortes disciplinares. Trad. Eduardo Lopes Piris e Moisés Olímpio Ferreira. EIDEA - Revista Eletrônica de Estudos Integrados em Discurso e Argumentação, Ilhéus, n. 1, p. 129-144, jun./nov. 2011.

. É possível integrar a argumentação na análise do discurso? Problemas e desafios. ReVEL, Edição especial, vol. 14, n. 12, 2016.

Apologia da polêmica. Trad. Mônica Magalhães Cavalcante et alii. São Paulo: Contexto, 2017.

A argumentação no discurso. Coord. de trad. Eduardo Lopes Piris e Moisés Olímpio-Ferreira.Ttrad. Angela M. S. Corrêa et alii. São Paulo: Contexto, 2018.

BAKHTIN, M. M. Problemas da poética de Dostoievski. Trad. P. Bezerra. Rio de Janeiro: Forense Universitária, 1997.

BRITO, M. A. P.; OLIVEIRA, R. L. A construção do referente em uma análise do pathos na polêmica. Organon, v. 33, p. 01-16, jan-jul/2018.

CABRAL, A. L. T.; LIMA, N. V. Interações conflituosas e violência verbal nas redes sociais: polêmica em comentários no Facebook. Contextos linguísticos, v. 12, p. 39-58, 2018. 
CAVALCANTE, M. M. Metadiscursividade, argumentação e referenciação. Estudos Linguísticos, São Paulo, v. 03, p. 345-354, set/dez, 2009.

. Referenciação: sobre coisas ditas e não ditas. Fortaleza: UFC, 2011.

Abordagens da argumentação nos estudos de Linguística Textual. In: ReVEL, edição especial, vol. 14, n. 12, p. 106-124, 2016.

. Linguística Textual e Argumentação. Encontro do GELNE. Natal/ RN, 2017.

.; et alii. Polêmica e Argumentação: Interfaces possíveis em textos midiáticos de natureza política. Diacrítica, v. 32, p. 05-24, 2018.

.; et alii. A negociação persuasiva para a análise da argumentação nos discursos.

Contextos linguísticos. V. 13, p. 99-116, 2019.

KOCH, I. G. V. Introdução à linguística textual. São Paulo: Martins Fontes, 2004.

MACEDO, P. S. A.; CAVALCANTE, M. M. Estratégias de textualização na polêmica sobre culturas agrícolas no Brasil. Entrepalavras, Fortaleza, v. 9, p. 303-320, n. 1, jan-abr/2019. MAINGUENEAU, D. L'analyse du discours. Paris: Hachette, 1991.

Análise de textos de comunicação. Trad. Cecília P. de Souza-e-Silva. 5.ed. São

Paulo: Cortez, 2008a

MARCUSCHI, L. A. Produção textual, análise de gêneros e compreensão. São Paulo: Parábola Editorial, 2008.

SILVA, A. A. Polêmica nas redes sociais: interações sobre o ataque ao candidato Jair Bolsonaro. Juçara, v. 2, p. 256-272, 2018.

Recebido em 05/03/2020.

Aprovado em 14/o7/2020. 